\title{
Partial Unilateral Lentiginous and Colon Polyp In A Young Male Patient
}

Gülhan Gürel', Sevinç Şahin², Emine Çölgeçen

${ }^{1}$ Department of Dermatology, Bozok University School of Medicine, Yozgat, Turkey

${ }^{2}$ Department of Pathology, Bozok University School of Medicine, Yozgat, Turkey
Corresponding author: Gülhan Gürel, Department of Dermatology, Medical Faculty, Bozok University, 66200 Yozgat, Turkey.

E-mail: gulhanozturkgurel@hotmail.com

\section{INTRODUCTION}

Partial unilateral lentiginosis (PUL) is an unusual pigmentary disorder characterized by numerous lentigines grouped within an area of normal skin [1]. It was first described by McKelway in 1904 in a patient with unilateral distribution [2]. It usually occurs at birth or during childhood. Cases with neurological abnormality or ocular involvement have been reported [3].

We describe a 17 -year-old male patient with a partial unilateral lentiginous lesion on the left side of the body and left upper back and incidental polyp in the descending colon.

\section{Case Report}

A 17-year-old male patient was admitted to our clinic with hyperpigmented macules on the left side of the body and left upper back the previous for 9 years. The patient had presented to the general surgery clinic due to abdominal pain approximately 1 year ago. Upper gastrointestinal system endoscopy and colonoscopy had been performed. Polyp was detected in the descending colon and histopathology was interpreted as tubular adenoma (Figure 1). The patient's medical history revealed no remarkable abnormalities. There were no hyperpigmented macules or similar intestinal polyps in his family. General physical examination was unremarkable. Laboratory test results were within normal limits. Dermatologic examination revealed a large number of millimetric macules on the left side of the body and left upper back (Figures 2,3). No other mucocutaneous abnormalities were noted. Neurological and ophthalmological examinations were normal. Punch biopsy was taken from the left side of the chest. Histological examination revealed orthokeratosis mild papillomatosis, slightly elongated rete ridges and hyperpigmentation of basilar keratinocytes (Figure 4).

PUL was diagnosed in the light of the clinical and histopathological findings. We interpret this case as an incidental combination of PUL and polyp in the descending colon.
Accepted: 28.12 .2017

DOI: $10.5799 /$ jcei.413079 


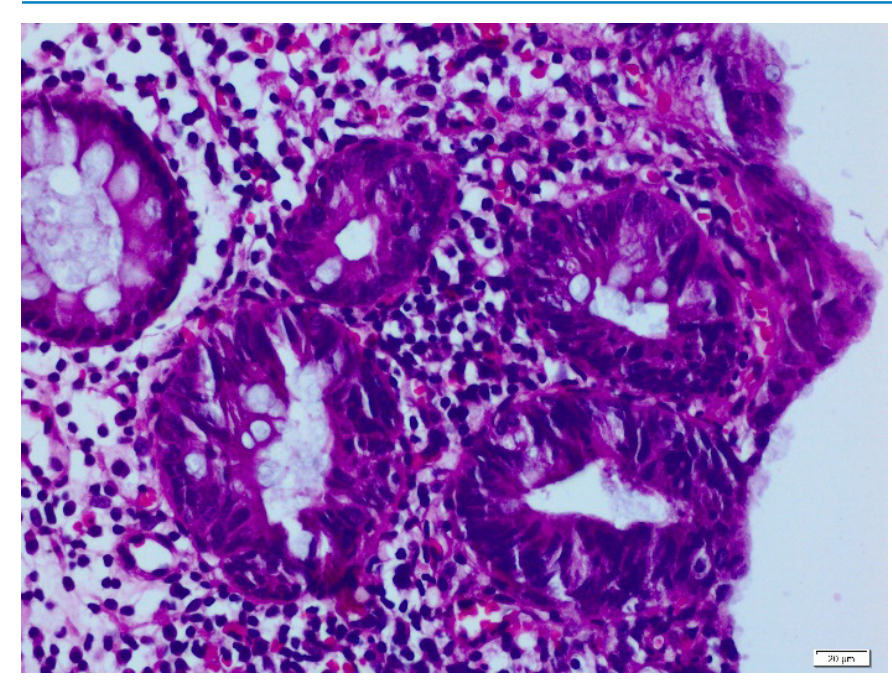

Figure 1. The photomicrograph of tubular adenoma in the descending colon (Hematoxylin \& Eosin stain, original magnification $\times 400)$.
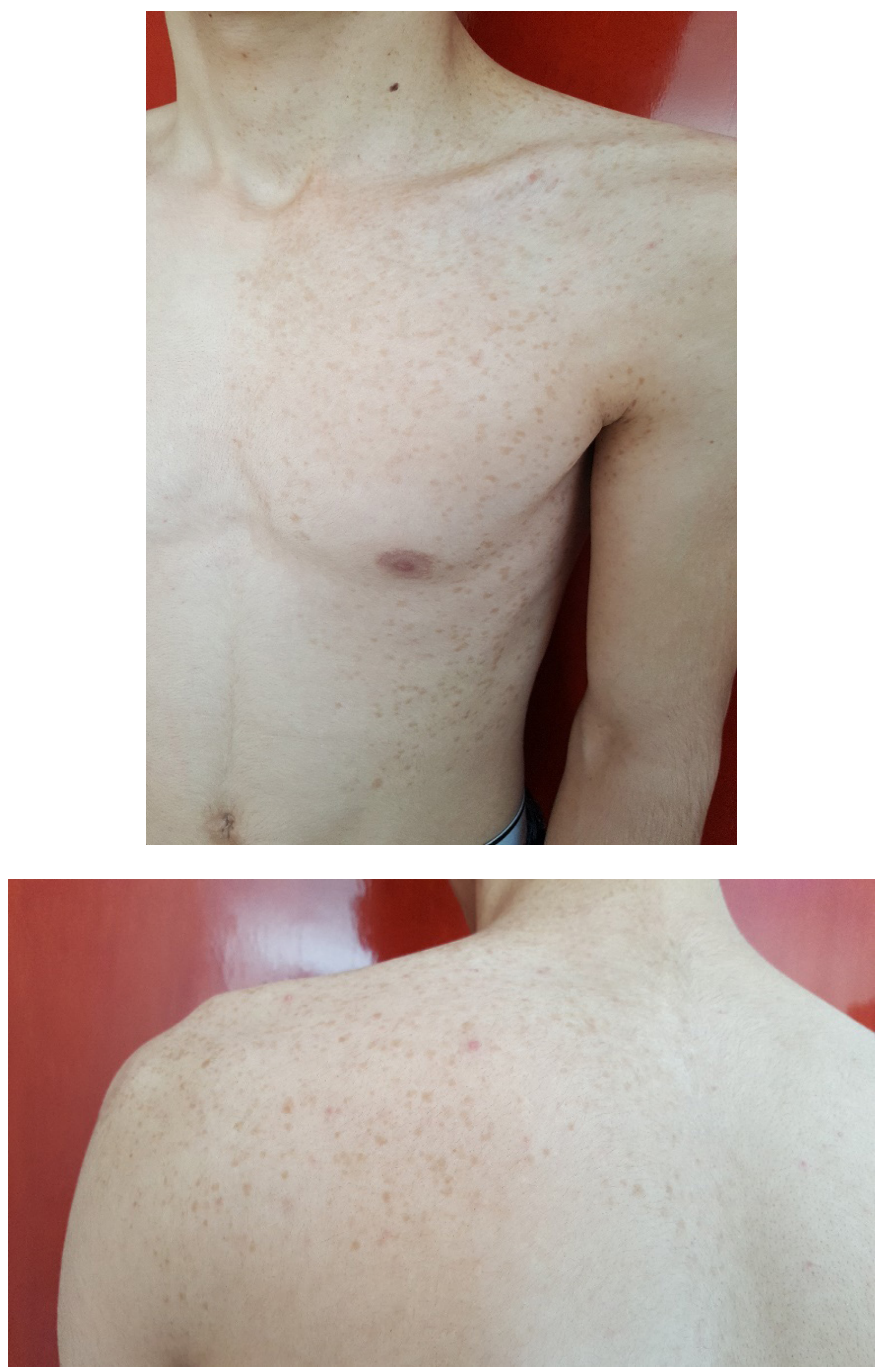

Figure $\mathbf{2}$ and Figure 3. Millimetric macules on the left side of the body and left upper back

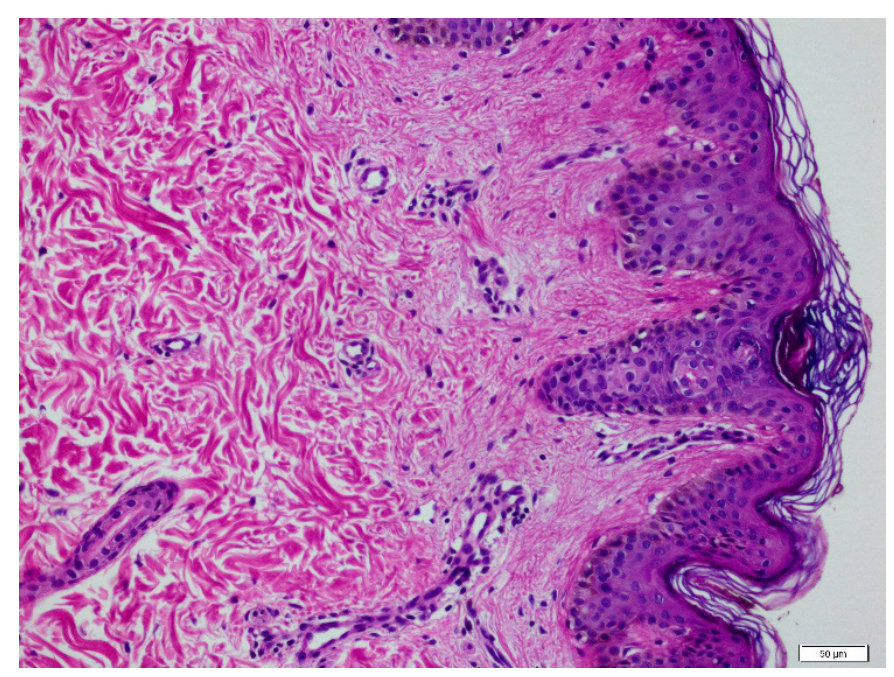

Figure 4. The photomicrograph of the punch skin biopsy illustrating orthokeratosis mild papillomatosis, slightly elongated rete ridges, and hyperpigmentation of basilar keratinocytes, (Hematoxylin \& Eosin stain, original magnification $\times 200$ ).

\section{DISCUSSION}

PUL is a macular pigmentation characterized by numerous lentigines on the upper extremities, where they are 3 times more common compared with the lower extremities [3]. The prevalence is similar in male and females [4]. The lesions generally occur during early childhood [5]. PUL should be differentiated from nevus spilus, which has a hyperpigmented background and a more stable course over the years, ${ }_{2}$ since the lesion grows in proportion to the patient [6]. Histologically, PUL exhibits a lentiginous epidermal proliferation of melanocytes and elongation of the rete ridges [7].

Various genetic disorders present with lentigines, such as Peutz-Jegher syndrome, Carney's complex, Leopard syndrome, segmental neurofibromatosis and centrofacial lentiginosis [6]. Our case differs from these diseases in that the lesion exhibit a typically unilateral and segmentary distribution. Neurological and ophthalmological examinations were normal.

Associations with café-au-lait spots, cutis marmorata, acanthosis nigricans, nevus depigmentosus, vitiligo, blue nevus, segmental neurofibromatosis, central nervous system diseases, celiac disease, and sickle cell anemia have been reported [1,3,4,8,9]. All accompanying diseases are thought to be incidental [3].

There is no standard treatment for this disease. Alexandrite Q-switched laser and Q-switched Nd:YAG laser systems have been used in the treatment of PUL with few side effects $[6,10]$.

We describe a 17-year-old male patient with a PUL and incidental polyp in the descending colon. In conclusion, while PUL is rare, our case is an extremely rare condition associated with polyp in the descending colon. 
Conflict of Interests: The authors declare that they have no conflict of interest.

Financial Disclosure: No financial support was received.

\section{REFERENCES}

1. Trattner A, Metzker A. Partial unilateral lentiginosis. J Am Acad Dermatol. 1993;29:693-5.

2. McKelway JL. Lentigo: unilateral distribution: report of a case. NY Med J 1904;80:197-8.

3. Schaffer JV, Lazova R, Bolognia JL. Partial unilateral lentiginosis with ocular involvement. J Am Acad Dermatol. 2001;44(s2):387-90.

4. Holder JE, Graham-Brown RA, Camp RD. Partial unilateral lentiginosis associated with blue naevi. Br J Dermatol. 1994;130:390-3.

5. Kim EH, Kang HY. Partial unilateral lentiginosis with ocular involvement. Eur J Dermatol. 2006;16:582-3.
6. Pretel M, Irarrazaval I, Aguado L, Lera JM, Navedo M, Giménez de Azcárate A. Partial unilateral lentiginosis treated with alexandrite Q-switched laser: case report and review of the literature. J Cosmet Laser Ther. 2013;15:207-9.

7. Mosher DB, Fitzpatrick TB, Ortonne J, Hori Y. Hypomelanoses and hypermelanoses. In: Freed berg IM, Eisen AZ, Wolff K,Austen KF, Goldsmith LA, et al, editors. Fitzpatrick's dermatology in general medicine. Fitzpatrick TB. 5th ed. New York, McGraw-Hill; 1999. p. 945-1017.

8. Alkemade H, Juhlin L. Unilateral lentiginosis with nevus depigmentosus on the other side. J Am Acad Dermatol. 2000;43:361-3.

9. Hughes GS Jr, Park HK, Jones BE. Partial unilateral lentiginosis in a black patient with sickle cell anemia. J Am Acad Dermatol. 1983;8:5635.

10. Suh DH, Han KH, Chung JH. The use of Q-switched Nd:YAG laser in the treatment of superficial pigmented lesions in Koreans. J Dermatolog Treat. 2001;12:91-6. 